\title{
Assessment of Lifestyle and Diet Modification of Patients Suffering from Polycystic Ovarian Disease (PCOD) in North India
}

\author{
Akriti Shrestha*, Anamika Dixit, Aamena Zaidi \\ Department of Nutrition Science, Chhatrapati Shahu Ji Maharaj University, Kanpur, India \\ Email address: \\ aakkushrestha@gmail.com (A. Shrestha) \\ ${ }^{*}$ Corresponding author
}

To cite this article:

Akriti Shrestha, Anamika Dixit, Aamena Zaidi. Assessment of Lifestyle and Diet Modification of Patients Suffering from Polycystic Ovarian Disease (PCOD) in North India. Journal of Food and Nutrition Sciences. Vol. 7, No. 4, 2019, pp. 60-65. doi: 10.11648/j.jfns.20190704.12

Received: September 16, 2019; Accepted: October 4, 2019; Published: October 15, 2019

\begin{abstract}
It is an established fact that the cause of Polycystic Ovarian Disease (PCOD) has a significant hereditary component. Various researchers have also revealed that PCOD is associated with obesity and successful weight reduction is the most effective method of restoring normal ovulation and menstruation. In the present study, an attempt is made to assess the general, anthropometric, biochemical and clinical observation along with lifestyle and dietary pattern of the patients. An association of PCOD with certain demographic variables is established through the survey of 50 women suffering from PCOD in Kanpur Urban Area of North India. After the data is acquired from the participants through structured questionnaire, a descriptive approach is implemented for the analysis. The methodology undertaken in the present study also involves dietary assessment of the participated women which was utilized for their classification into different nutritional status (undernourished, nourished and over-nourished). In the present work, we first present the percentage of participants belonging to different groups and sub-groups based on general, anthropometric, biochemical and clinical examinations. Next, we demonstrate the association of PCOD with different demographic variables based on nutritional status of the participants. A hypothesis that there would be a significant association between PCOD with different demographic variables is established from the results of the association.
\end{abstract}

Keywords: PCOD, Lifestyle, Dietary Pattern, Association

\section{Introduction}

Patients suffering from polycystic ovarian disease (PCOD) or also known as functional ovarian hyperandrogenism, ovarian hyperthecosis and sclerocystic ovary syndrome have multiple small cysts in their ovaries. These cysts occur when the regular changes of a normal menstrual cycle are interrupted. The ovary is inflated; and produces a large amounts of androgen and estrogenic hormones. This excess, along with the absence of ovulation, may cause sterility in women. The condition was first described in 1935 by American gynecologists Irving F. Stein, Sr. and Michael L. Leventhal, from whom it's original name: Stein-Leventhal syndrome is taken [1]. Recently, the European Society for Human Reproduction and Embryology (ESHRE) and the American Society for Reproductive Medicine (ASRM) achieved a new consensus regarding the definition of PCOD which is now defined as the presence of any two of the following three criteria: (i) polycystic ovaries; (ii) oligo/anovulation; and/or (iii) clinical or biochemical evidence of hyperandrogenism [2]. This revised definition offers an international basis for the clinical assessment of PCOD as well as all sort of research and collaboration.

The prevalence of PCOD depends on the choice of diagnostic criteria. The World Health Organization estimates that it affects 116 million women worldwide as of 2010 (3.4\% of women) [3]. One community-based prevalence study found that about $18 \%$ of women had PCOD, and that $70 \%$ of them were previously undiagnosed [4]. Ultrasonographic findings of polycystic ovaries are found in $8-25 \%$ of normal women [5-8]. $14 \%$ women on oral contraceptives are found to have polycystic ovaries [6]. 
On the one hand, it's a well-known fact that the root cause of PCOD has a substantial hereditary factor, and is often transmitted from mother to daughter. Barbieri is one of the first persons to study about PCOD [9]. According to the author, PCOD is a common endocrinopathy in women of reproductive age. Regarding the genetic connection of PCOD a few studies in literature are relevant. Battaglia et al. [10] discovered that polycystic ovaries in childhood may be considered a sign of genetic predisposition to PCOD and that environmental influences may express the adult clinical and hormonal presentation of the syndrome. Study conducted by Vink et al. [11] also showed that the contribution of familial component in PCOD is due to genetic factors.

On the other hand, many studies [12-15] have suggested that lifestyle modification and dietary treatment of women with PCOD was the best initial management for obese women seeking to improve their reproductive function. Study of lifestyle modifications by use of alteration of diet intake and exercise therapy to treat obese women with PCOD were successfully employed by Palomba et al. [16], Thomson et al. [17], Hoeger et al. [18] and Giallauria et al. [19] as well. Likewise, there has been a few community based studies of the PCOD suffered women in India so far [20-24]. However, a systematic study of association of PCOD with the sociodemographic variables of the PCOD suffering patients based on the different categories of nourishment levels is lagging in the literature.

Thus, we set the objectives of the present study as: to assess the general, anthropometric, biochemical, clinical, lifestyle and dietary pattern of the patient suffering from PCOD and to compute the association of PCOD with certain demographic variables at different levels of nourishments. Also we hypothesize that there will be a significant association between the patients suffering from PCOD with different demographic variables. To our knowledge, this is the first study of this kind conducted in the Indian subcontinent.

\section{Materials and Methods}

\subsection{Research Settings}

Descriptive approach is utilized in this study. The study is conducted in Krishna Hospital of Kanpur, Uttar Pradesh, India. The population of study is the female diagnosed with PCOD and undergoing treatment. The sample size is 50 .

\subsection{Statistical Analysis}

Non-probability convenient sampling technique is used in this study. Structured questionnaire is used to collect the data. The plan for data analysis is carried out using descriptive statistics and inferential statistics. The investigation is carried further to find out the association between lifestyle and diet modification in the development of PCOD with selected demographic variables. For the analysis of association based on observed data, Chi-square $\left(\chi^{2}\right)$ test is performed and tabulated. The degree of freedom (DF) for calculating the values of $\chi^{2}$ for different categories is also mentioned in the same table (in the upcoming sections). The $\chi^{2}$ value is then compared with the table value of significance at $0.05(\mathrm{Sf})$ in order to evaluate the factuality of our hypothesis.

\subsection{Socio-economic and Demographic Information}

A questionnaire was prepared to collect the general information like age, religion, lifestyle, occupation, education level, family history of PCOD, income group, menstruation duration, marital status and reproductive issues (if any) from the participants. Bio-chemical results of Luteinizing hormone to Follicle-stimulating hormone (LH-FSH) ratio was also acquired from the patients. Anthropometrical data were collected in terms of body height, weight and BMI. Finally the clinical examination of the participants with the help of experienced physicians and nurses was carried out. The general appearance, hair quality, appetite, face skin and body hair was observed and the participants were categorized into different sub-groups based on that scrutiny.

\subsection{Dietary Assessment}

Dietary data are acquired by recording the information of food consumed by patients in 3 consecutive days. 24-hour dietary recall sessions for 3 days was used for the information. The reported information of food quantities in terms of plates, bowls and glasses was converted into equivalent scientific quantities of grams and calories by following a standard conversion technique.

\subsection{Nutritional Status}

Nutritional status of the patients was assessed according to various demographic variables. The participants are classified as under-nourished (Ur), Nourished (Nr) and Overnourished (Or) based on the dietary data.

\section{Results}

The information obtained from the survey of patients is used to classify them into different categories on the basis of various demographic variables. Table 1 demonstrates the percentage of women belonging to different groups and subgroups based on general, bio-chemical, anthropometric and clinical examinations. It is revealed that more than two-third women in survey were of age group 20-40 years and almost the same proportion of women had sedentary lifestyle. In terms of occupation, $58 \%$ of the women were house-wives while $28 \%$ were working as employee and rest had their own businesses. The information about the education level showed that only $12 \%$ were college graduates while almost a quarter of the participants were illiterate.

Correspondingly, while we asked them about the family history of PCOD (if any), $28 \%$ of them told that there was someone in their family and/or relatives who suffered from PCOD prior to them, while nearly half of the participants didn't know about their family history regarding PCOD. In terms of economic state all of the participants were either 
high class or middle class. Also, majority of them were married and the equal number of them had menstruation problem with menstruation duration being two months. In the similar manner, the results related to anthropometry and clinical examination also revealed some interesting features as indicated in table 1.

Likewise, table 2 depicts the results of division of participants into different categories and sub-categories based on their responses to our questionnaire related to the dietary patterns, lifestyle and habits of performing exercise or yoga.

Table 1. Details on the division of participants into the different categories based on general, bio-chemical, anthropometric and clinical observation.

\begin{tabular}{|c|c|c|c|c|c|c|c|c|}
\hline SN & Categories & $\%$ & SN & Categories & $\%$ & SN & Categories & $\%$ \\
\hline 1 & Age in years & & 8 & Menstruation Duration & & 14 & BMI & \\
\hline $\mathrm{a}$ & $<20$ & 8 & $\mathrm{a}$ & $1 / 2$ month & 0 & $\mathrm{a}$ & Below 16 & 0 \\
\hline $\mathrm{b}$ & $20-30$ & 42 & $\mathrm{~b}$ & 1 month & 18 & $\mathrm{~b}$ & $16-20$ & 0 \\
\hline $\mathrm{c}$ & $30-40$ & 26 & $\mathrm{c}$ & 2 months & 82 & $\mathrm{c}$ & $20-25$ & 26 \\
\hline d & $>40$ & 24 & $\mathrm{~d}$ & 3 months & 0 & d & $25-30$ & 68 \\
\hline 2 & Religion & & 9 & Marital Status & & $\mathrm{e}$ & Over 30 & 6 \\
\hline $\mathrm{a}$ & Hindu & 68 & $\mathrm{a}$ & Married & 72 & 15 & General Appearance & \\
\hline$b$ & Muslim & 30 & $\mathrm{~b}$ & Unmarried & 28 & $\mathrm{a}$ & Good & 62 \\
\hline $\mathrm{c}$ & Christian & 2 & $\mathrm{c}$ & Divorced & 0 & $\mathrm{~b}$ & Fair & 24 \\
\hline d & Buddhist & 0 & $\mathrm{~d}$ & Widow & 0 & $\mathrm{c}$ & Poor & 14 \\
\hline 3 & Lifestyle & & 10 & Reproductive Issue* & & $\mathrm{d}$ & Very Poor & 0 \\
\hline $\mathrm{a}$ & Sedentary & 72 & $\mathrm{a}$ & Fertility Issue & 11.11 & 16 & Hair & \\
\hline $\mathrm{b}$ & Moderate & 28 & $\mathrm{~b}$ & Miscarriage & 5.56 & $\mathrm{a}$ & Normal & 0 \\
\hline $\mathrm{c}$ & Heavy & 0 & $\mathrm{c}$ & None & 83.33 & $\mathrm{~b}$ & Loss of luster & 8 \\
\hline 4 & Occupation & & 11 & LH:FSH & & $\mathrm{c}$ & Discolor and dry & 26 \\
\hline $\mathrm{a}$ & Government Job & 8 & $\mathrm{a}$ & $1: 01$ & 0 & $\mathrm{~d}$ & Alopecia & 66 \\
\hline $\mathrm{b}$ & Private Job & 20 & $\mathrm{~b}$ & $2: 01$ & 86 & 17 & Appetite & \\
\hline $\mathrm{c}$ & Business & 14 & $\mathrm{c}$ & $3: 01$ & 14 & $\mathrm{a}$ & Normal & 44 \\
\hline d & House-wife & 58 & $\mathrm{~d}$ & $4: 01$ & 0 & $\mathrm{~b}$ & Anorexia & 56 \\
\hline 5 & Education & & 12 & Height $(\mathrm{cm})$ & & 18 & Face $^{\#}$ & \\
\hline $\mathrm{a}$ & High School & 38 & $\mathrm{a}$ & $<140$ & 0 & $\mathrm{a}$ & Normal & 8 \\
\hline$b$ & Intermediate & 26 & $\mathrm{~b}$ & $140-150$ & 14 & $\mathrm{~b}$ & Nasolabial seborrhea & 0 \\
\hline $\mathrm{c}$ & Graduate & 12 & $\mathrm{c}$ & $150-160$ & 66 & $\mathrm{c}$ & Moon Face & 74 \\
\hline $\mathrm{d}$ & Illiterate & 24 & $\mathrm{~d}$ & $160-170$ & 18 & $\mathrm{~d}$ & Pimple/Acne & 92 \\
\hline 6 & Family history of PCOD & & $\mathrm{e}$ & $170-180$ & 2 & 19 & Skin $^{\#}$ & \\
\hline $\mathrm{a}$ & Present & 28 & 13 & Body weight (kg) & & a & Normal & 54 \\
\hline $\mathrm{b}$ & Absent & 26 & $\mathrm{a}$ & Below 45 & 0 & $\mathrm{~b}$ & Loss of luster & 0 \\
\hline $\mathrm{c}$ & Don’t Know & 46 & $\mathrm{~b}$ & $45-55$ & 18 & $\mathrm{c}$ & Dry \& Rough & 34 \\
\hline 7 & Income group & & $\mathrm{c}$ & $55-65$ & 34 & $\mathrm{~d}$ & Hyperkeratosis, Phrynoderma & 50 \\
\hline $\mathrm{a}$ & High & 32 & $\mathrm{~d}$ & $65-75$ & 42 & 20 & Face/Body Hair & \\
\hline $\mathrm{b}$ & Medium & 68 & $\mathrm{e}$ & Over 75 & 6 & $\mathrm{a}$ & Normal & 18 \\
\hline c & Low & 0 & & & & $\mathrm{~b}$ & Hirsutism & 8 \\
\hline
\end{tabular}

*Percentage of married women only; ${ }^{*}$ Multiple category assigned for single participant

Table 2. Details on the division of participants into the different categories based on dietary pattern and lifestyle.

\begin{tabular}{|c|c|c|c|c|c|c|c|c|}
\hline $\mathbf{S N}$ & Categories & $\%$ & SN & Categories & $\%$ & SN & Categories & $\%$ \\
\hline 1 & Dietary Pattern & & 6 & Junk consumption & & 11 & Smoking habit & \\
\hline $\mathrm{a}$ & Vegetarian & 50 & $\mathrm{a}$ & Daily & 0 & $\mathrm{a}$ & Yes & 8 \\
\hline $\mathrm{b}$ & Non-vegetarian & 42 & $\mathrm{~b}$ & Twice a week & 18 & $\mathrm{~b}$ & No & 92 \\
\hline $\mathrm{c}$ & Eggitarian & 8 & $\mathrm{c}$ & Occasionally & 70 & 12 & \multicolumn{2}{|c|}{ Alcohol consumption Frequency } \\
\hline 2 & Frequency to non-veg ${ }^{\$}$ & & $\mathrm{~d}$ & Never & 12 & $\mathrm{a}$ & Daily & 0 \\
\hline $\mathrm{a}$ & Daily & 0 & 7 & Type of oil used & & $\mathrm{b}$ & Twice a week & 0 \\
\hline $\mathrm{b}$ & Twice a week & 19. & $\mathrm{a}$ & Refined & 62 & $\mathrm{c}$ & Thrice a week & 0 \\
\hline $\mathrm{c}$ & Thrice a week & 19.1 & $\mathrm{~b}$ & Olive oil & 0 & $\mathrm{~d}$ & Occasionally & 14 \\
\hline d & Weekly & 52.4 & $\mathrm{c}$ & Mustard oil & 38 & $\mathrm{e}$ & Never & 86 \\
\hline e & Rarely & 9.5 & $\mathrm{~d}$ & Dalda & 0 & 13 & Exercise Habit & \\
\hline 3 & Affinity to meat & & 8 & Cooking Method & & $\mathrm{a}$ & Daily & 6 \\
\hline $\mathrm{a}$ & Red meat & 14.3 & $\mathrm{a}$ & Steaming & 18 & $\mathrm{~b}$ & Twice a week & 16 \\
\hline $\mathrm{b}$ & White meat & 85.7 & $\mathrm{~b}$ & Roasting & 42 & $\mathrm{c}$ & Never & 78 \\
\hline $\mathrm{c}$ & Any other & 0 & $\mathrm{c}$ & Deep Frying & 86 & 14 & Yoga Performar & \\
\hline 4 & Habit of Breakfast & & $\mathrm{d}$ & Pressure cooking & 94 & $\mathrm{a}$ & Daily & 6 \\
\hline a. & Daily & 56 & 9 & \multicolumn{2}{|c|}{ Frequency of eating green vegetables } & $\mathrm{b}$ & Twice a week & 16 \\
\hline b. & Twice a week & 16 & $\mathrm{a}$ & Daily & 42 & $\mathrm{c}$ & Never & 78 \\
\hline c. & Thrice a week & 22 & $\mathrm{~b}$ & Twice a week & 54 & 15 & Chronic Diseas & \\
\hline d. & Never & 6 & $\mathrm{c}$ & Never & 4 & $\mathrm{a}$ & CVD & 18 \\
\hline 5 & Food Preference ${ }^{\#}$ & & 10 & Habit of eating fruit & & $\mathrm{b}$ & Diabetes & 32 \\
\hline $\mathrm{a}$ & Sweet & 86 & $\mathrm{a}$ & Daily & 42 & $\mathrm{c}$ & Renal Disease & 0 \\
\hline $\mathrm{b}$ & Salty & 68 & $\mathrm{~b}$ & Twice a week & 58 & $\mathrm{~d}$ & GIT disorder & 6 \\
\hline
\end{tabular}




\begin{tabular}{|c|c|c|c|c|c|c|c|c|}
\hline SN & Categories & $\%$ & SN & Categories & $\%$ & SN & Categories & $\%$ \\
\hline c & Spicy & 18 & $\mathrm{c}$ & Never & 0 & e & Any Other & 0 \\
\hline d & Sour & 12 & & & & $\mathrm{f}$ & None & 44 \\
\hline e & All & 0 & & & & & & \\
\hline
\end{tabular}

${ }^{\text {S}}$ Percentage of non-vegetarians only; ${ }^{*}$ Multiple category assigned for single participant

Next, the patients of different demographic groups are divided into different levels of nourishment based on various nutrients intake. The data of 24 hours dietary recall for 3 days was used to perform this division where, the required level of energy for the patients of corresponding age group and weight as per the standards of Indian Council of Medical Research (ICMR) was utilized.

Table 3 illustrates the distribution of patients as under- nourished (Ur), nourished (Nr) and over-nourished (Or) as shown:

Table 3. Distribution of patients into different levels of nourishment.

\begin{tabular}{lll}
\hline S. No. & Nutritional status & Percentage \\
\hline 1. & Under-nourished (Ur) & $0 \%$ \\
2. & Nourished (Nr) & $36 \%$ \\
3. & Over-nourished (Or) & $64 \%$ \\
\hline
\end{tabular}

Table 4. Frequency distribution of nourishment level of patients of different ages corresponding to different nutrients.

\begin{tabular}{|c|c|c|c|c|c|c|c|c|c|c|}
\hline \multirow{2}{*}{ SN } & \multirow{2}{*}{$\begin{array}{l}\text { Nutrients }(\downarrow) \\
\text { Age in years }(\rightarrow)\end{array}$} & \multicolumn{4}{|c|}{ Nourished (Nr) } & \multicolumn{4}{|c|}{ Over-nourished (Or) } & \multirow{2}{*}{ Mean } \\
\hline & & $<\mathbf{2 0}$ & 20-30 & $30-40$ & $>40$ & $<\mathbf{2 0}$ & 20-30 & $30-40$ & $>40$ & \\
\hline 1 & Energy & 1 & 7 & 7 & 3 & 3 & 14 & 6 & 9 & $2650 \mathrm{Cal}$. \\
\hline 2 & $\mathrm{CHO}$ & 2 & 8 & 7 & 1 & 2 & 13 & 6 & 11 & $245 \mathrm{gm}$ \\
\hline 3 & Protein & 2 & 13 & 8 & 7 & 2 & 8 & 5 & 5 & $67 \mathrm{gm}$ \\
\hline 4 & Fat & 2 & 9 & 9 & 4 & 2 & 12 & 4 & 8 & $23 \mathrm{gm}$ \\
\hline
\end{tabular}

\section{Discussion of the Results}

The objectives of the present study were to assess the anthropometric, biochemical, clinical, life-style and dietary pattern of the patient suffering from PCOD and to compute the association of PCOD with certain demographic variables of the same categories. To our knowledge, this is the first study in the Indian sub-continent to access the sociodemographic variables of PCOD suffering patients and to estimate the association of PCOD with these variables by classifying the patients into different categories of nourishment level. Initially, the general information of patients under survey was collected. Age, religion, life-style, occupation, education level, income level, etc. of the patients was inquired. The main motivation for this study is to get the overview of the group of patients suffered from PCOD and getting treatment at Krishna Hospital, Kanpur in North India. Further analysis of results regarding the life-style and occupation of the patients revealed that, majority of them were having sedentary life-style and main stream were house-wives. A significant comparison between these aspects and their suffering from PCOD can be made. A hypothesis of relation between the physical activities of the patients and their suffering from PCOD is also revealed from association analysis as well. However, the study of some variables were not successful for example an attempt to perceive the association between PCOD suffering and family history of the same couldn't be made precisely because almost half of the patients didn't have idea regarding their family history. Nevertheless, some well-established facts like menstruation duration and reproductive health related issues during PCOD gave consistent results.

In the similar manner, anthropometry of the patients is carried out. BMI of majority of the patients was observed to be more than the recommended safe value. Clinical examination of appearance, hair, face and skin revealed some interesting data. It is observed that majority of the patients have good general appearance. Similarly, discolour and dry hair is observed for around a quarter of the patients. Additionally, alopecia is observed for majority of the patients under survey. Moreover, half of the patients were having normal appetite while anorexia was observed for almost remaining half. Similarly, the skin observation of the patients revealed that $50 \%$ of them were having Hyperkeratosis and Phrynoderma. Hair related issues including face and body hair was observed in a few patients as well.

Next, dietary information of the patients was collected and analysed. $50 \%$ of them were found to be vegetarian. It was also revealed that majority of those who have nonvegetarian food use to consume the same once in a week. Moreover, $85 \%$ of those who consume non-vegetarian food were fond of white meat rather than red meat. The patients' preference of food revealed that almost all of them like sweet food. Majority of them like salty food and very few of them like spicy and sour food. Additionally, 70\% of the patients said that they like consuming junk food occasionally. Information regarding the oil used by them for cooking revealed that they use either refined oil or mustard oil. Similarly, cooking method adopted by them as well as habit of eating fruits and green leafy vegetables is also studied.

Life-style of the patients including the habits of smoking and alcohol consumption is enquired. It was socking to notice that many patients (around 78\%) never perform any sorts of physical exercise or yoga. In the similar manner, chronic diseases suffering in the patients of PCOD is discussed. $18 \%$ of them were suffering from CVD while $32 \%$ of them were suffering from diabetes. Around $44 \%$ of them were not suffering from any chronic diseases. 
The results obtained from the survey was used to find the association of the suffering of PCOD in women with various demographic variables. Patients were classified into different categories of nourishment level as under-nourished, nourished and over-nourished. It was observed that there were no patients who were under-nourished.
Correspondingly, 32 of them were over-nourished and remaining 18 were nourished. The results obtained from association were found to be consistent with the overall observation. Moreover, the obtained value of $\chi^{2}$ for all categories was found to be lesser than the table value, thus establishing the validity of our hypothesis postulated initially.

Table 5. Association of demographic variables with PCOD of the patients of different levels of nourishment.

\begin{tabular}{|c|c|c|c|c|c|c|c|c|c|c|c|c|c|c|c|}
\hline $\mathbf{S N}$ & & Ur & $\mathrm{Nr}$ & Or & $\Sigma$ & $\chi^{2}(D F)$ & Sf & SN & & Ur & $\mathrm{Nr}$ & Or & $\Sigma$ & $\chi^{2}(D F)$ & Sf \\
\hline A & Age (years) & & & & & \multirow{6}{*}{$\begin{array}{l}7.5 \\
(6 D F)\end{array}$} & \multirow{6}{*}{12.6} & G & Dietary pattern & & & & & \multirow{5}{*}{$\begin{array}{l}1.4 \\
(4 D F)\end{array}$} & \multirow{5}{*}{9.5} \\
\hline 1 & $<20$ & 0 & 1 & 3 & 4 & & & 1 & Veg. & 0 & 11 & 14 & 25 & & \\
\hline 2 & $20-30$ & 0 & 7 & 14 & 21 & & & 2 & N-Veg. & 0 & 6 & 15 & 25 & & \\
\hline 3 & $30-40$ & 0 & 7 & 6 & 13 & & & 3 & Eggetarian & 0 & 1 & 3 & 4 & & \\
\hline \multirow[t]{2}{*}{4} & $>40$ & 0 & 3 & 9 & 12 & & & & Total & 0 & 18 & 32 & 50 & & \\
\hline & Total & 0 & 18 & 32 & 50 & & & $\mathrm{H}$ & \multicolumn{2}{|l|}{ Breakfast frequency } & & & & \multirow{6}{*}{$\begin{array}{l}1.8 \\
(6 D F)\end{array}$} & \multirow{6}{*}{12.6} \\
\hline B & Life-style & & & & & & & 1 & Daily & 0 & 7 & 21 & 28 & & \\
\hline 1 & Sedentary & 0 & 7 & 7 & 14 & \multirow{4}{*}{$\begin{array}{l}1.3 \\
(6 D F)\end{array}$} & \multirow{4}{*}{9.5} & 2 & Twice a week & 0 & 4 & 4 & 8 & & \\
\hline 2 & Moderate & 0 & 11 & 25 & 36 & & & 3 & Thrice a week & 0 & 5 & 6 & 11 & & \\
\hline \multirow[t]{2}{*}{3} & Heavy & 0 & 0 & 0 & 0 & & & 4 & Never & 0 & 2 & 1 & 3 & & \\
\hline & Total & 0 & 18 & 32 & 50 & & & & Total & 0 & 18 & 32 & 50 & & \\
\hline $\mathrm{C}$ & Occupation & & & & & \multirow{6}{*}{$\begin{array}{l}2.2 \\
(6 D F)\end{array}$} & \multirow{6}{*}{12.6} & I & Exercise & & & & & \multirow{6}{*}{$\begin{array}{l}0.7 \\
(6 \mathrm{DF})\end{array}$} & \multirow{6}{*}{12.6} \\
\hline 1 & Govt. Job & 0 & 2 & 2 & 4 & & & 1 & Daily & 0 & 0 & 3 & 3 & & \\
\hline 2 & Private Job & 0 & 3 & 7 & 10 & & & 2 & Twice a week & 0 & 3 & 5 & 8 & & \\
\hline 3 & Business & 0 & 4 & 3 & 7 & & & 3 & Thrice a week & 0 & 0 & 0 & 0 & & \\
\hline \multirow[t]{2}{*}{4} & House wife & 0 & 9 & 20 & 29 & & & 4 & Never & 0 & 15 & 24 & 39 & & \\
\hline & Total & 0 & 18 & 32 & 50 & & & & Total & 0 & 18 & 32 & 50 & & \\
\hline $\mathrm{D}$ & Family history & & & & & & & $\mathrm{J}$ & Yoga & & & & & & \\
\hline 1 & Present & 0 & 6 & 8 & 14 & \multirow{3}{*}{$\begin{array}{l}0.4 \\
(2 D F)\end{array}$} & \multirow{3}{*}{6} & 1 & Daily & 0 & 0 & 3 & 3 & \multirow{4}{*}{$\begin{array}{l}0.7 \\
(6 D F)\end{array}$} & \multirow{4}{*}{12.6} \\
\hline 2 & Absent & 0 & 12 & 24 & 36 & & & 2 & Twice a week & 0 & 3 & 5 & 8 & & \\
\hline & Total & 0 & 18 & 32 & 50 & & & 3 & Thrice a week & 0 & 0 & 0 & 0 & & \\
\hline $\mathrm{E}$ & Marital status & & & & & & & 4 & Never & 0 & 15 & 24 & 39 & & \\
\hline 1 & Married & 0 & 11 & 25 & 36 & \multirow{5}{*}{$\begin{array}{l}1.3 \\
(6 D F)\end{array}$} & & & Total & 0 & 18 & 32 & 50 & \multirow{12}{*}{$\begin{array}{l}2.6 \\
(10 \mathrm{DF})\end{array}$} & \multirow{12}{*}{16.9} \\
\hline 2 & Unmarried & 0 & 7 & 7 & 14 & & & $\mathrm{~K}$ & Chronic diseases & & & & & & \\
\hline 3 & Divorced & 0 & 0 & 0 & 0 & & 12.6 & 1 & CVD & 0 & 4 & 5 & 9 & & \\
\hline \multirow[t]{2}{*}{4} & Widowed & 0 & 0 & 0 & 0 & & & 2 & Diabetes Mellitus & 0 & 6 & 10 & 16 & & \\
\hline & Total & 0 & 18 & 32 & 50 & & & 3 & Renal disease & 0 & 0 & 0 & 0 & & \\
\hline $\mathrm{F}$ & Body Mass Ind & ex $(B$ & & & & & & 4 & GIT Disorder & 0 & 2 & 1 & 3 & & \\
\hline 1 & $<16$ & 0 & 0 & 0 & 0 & & & 5 & Any other & 0 & 0 & 0 & 0 & & \\
\hline 2 & $16-19.9$ & 0 & 0 & 0 & 0 & & & 6 & None & 0 & 6 & 16 & 22 & & \\
\hline 3 & $20-25$ & 0 & 5 & 8 & 13 & 1.4 & 155 & & Total & 0 & 18 & 32 & 50 & & \\
\hline 4 & $25-30$ & 0 & 10 & 14 & 24 & $(8 D F)$ & 15.5 & & & & & & & & \\
\hline 5 & $>30$ & 0 & 3 & 10 & 13 & & & & & & & & & & \\
\hline & Total & 0 & 18 & 32 & 50 & & & & & & & & & & \\
\hline
\end{tabular}

\section{Conclusion}

A study on life-style and diet modification on the patients suffering from PCOD was conducted on Krishna Hospital of Kanpur, North India. Sample data from 50 patients was collected. Questionnaire related to general information, anthropometry, biochemical examination, clinical examination, dietary information and life-style information along with 24 hours diet recall for 3 days was taken. The data revealed the significant association between PCOD suffering with some variables like age, life-style, occupation, family history of PCOD, marital status, BMI, dietary pattern, habit of taking breakfast, exercise, yoga, suffering from any of the chronic diseases, etc. In the near future, we plan to perform a similar study with a larger sample or population along with the research setting based on different locations/nations which can give us the better insight of the investigation in this field.

\section{List of Abbreviations}

PCOD: Polycystic Ovarian Disease

Govt. Job: Governmental Job

Veg.: Vegetarian

N-Veg.: Non-Vegetarian

CVD: Cardiovascular disease

GIT: Gastrointestinal

Sf:: Significance at 0.05

Ur: Under-nourished

Nr: Nourished

Or: Over-nourished

DF: Degree of freedom

\section{Acknowledgements}

The authors would like to acknowledge the administration as well as all staffs of Krishna Hospital, Kanpur for the access and support to carry out the research. Also, we would 
like to thank the participants and the overall resources of the department at Chhatrapati Shahu Ji Maharaj University, Kanpur.

\section{References}

[1] Marrinan, G., Imaging in Polycystic Ovary Disease. Eugene C. Lin. eMedicine.

[2] Hart, R., Hickey, M. and Franks, S., 2004. Definitions, prevalence and symptoms of polycystic ovaries and polycystic ovary syndrome. Best Practice \& Research Clinical Obstetrics \& Gynaecology, 18 (5), pp. 671-683.

[3] Vos, T., Flaxman, A. D., Naghavi, M., Lozano, R., Michaud, C., Ezzati, M., Shibuya, K., Salomon, J. A., Abdalla, S., Aboyans, V. and Abraham, J., 2012. Years lived with disability (YLDs) for 1160 sequelae of 289 diseases and injuries 1990-2010: a systematic analysis for the Global Burden of Disease Study 2010. The lancet, 380 (9859), pp. 2163-2196.

[4] Teede, H., Deeks, A., \& Moran, L. (2010). Polycystic ovary syndrome: a complex condition with psychological, reproductive and metabolic manifestations that impacts on health across the lifespan. BMC medicine, $8(1), 41$.

[5] Polson, D. W., Wadsworth, J., Adams, J. and Franks, S., 1988. Polycystic ovaries - a common finding in normal women. The Lancet, 331 (8590), pp. 870-872.

[6] Clayton, R. N., Ogden, V., Hodgkinson, J., Worswick, L., Rodin, D. A., Dyer, S. and Meade, T. W., 1992. How common are polycystic ovaries in normal women and what is their significance for the fertility of the population?. Clinical Endocrinology, 37 (2), pp. 127-134.

[7] Farquhar, C. M., Birdsall, M., Manning, P., Mitchell, J. M. and France, J. T., 1994. The prevalence of polycystic ovaries on ultrasound scanning in a population of randomly selected women. Australian and New Zealand Journal of Obstetrics and Gynaecology, 34 (1), pp. 67-72.

[8] Van Santbrink, E. J., Hop, W. C. and Fauser, B. C., 1997. Classification of normogonadotropic infertility: polycystic ovaries diagnosed by ultrasound versus endocrine characteristics of polycystic ovary syndrome. Fertility and sterility, 67 (3), pp. 452-458.

[9] Barbieri, R. L., 1991. Polycystic ovarian disease. Annual review of medicine, 42 (1), pp. 199-204.

[10] Battaglia, C., Regnani, G., Mancini, F., Iughetti, L., Flamigni, C. and Venturoli, S., 2002. Polycystic ovaries in childhood: a common finding in daughters of PCOS patients. A pilot study. Human Reproduction, 17 (3), pp. 771-776.

[11] Vink, J. M., Sadrzadeh, S., Lambalk, C. B. and Boomsma, D. I., 2006. Heritability of polycystic ovary syndrome in a Dutch twin-family study. The Journal of Clinical Endocrinology \& Metabolism, 91 (6), pp. 2100-2104.

[12] Kiddy, D. S., Hamilton - Fairley, D., Bush, A., Short, F., Anyaoku, V., Reed, M. J. and Franks, S., 1992. Improvement in endocrine and ovarian function during dietary treatment of obese women with polycystic ovary syndrome. Clinical endocrinology, 36 (1), pp. 105-111.
[13] Huber-Buchholz, M. M., Carey, D. G. P. and Norman, R. J., 1999. Restoration of reproductive potential by lifestyle modification in obese polycystic ovary syndrome: role of insulin sensitivity and luteinizing hormone. The Journal of Clinical Endocrinology \& Metabolism, 84 (4), pp. 1470-1474.

[14] Norman, R. J., Davies, M. J., Lord, J. and Moran, L. J., 2002. The role of lifestyle modification in polycystic ovary syndrome. Trends in Endocrinology \& Metabolism, 13 (6), pp. 251-257.

[15] Mavropoulos, J. C., Yancy, W. S., Hepburn, J. and Westman, E. C., 2005. The effects of a low-carbohydrate, ketogenic diet on the polycystic ovary syndrome: a pilot study. Nutrition \& metabolism, 2 (1), p. 35.

[16] Palomba, S., Giallauria, F., Falbo, A., Russo, T., Oppedisano, R., Tolino, A., Colao, A., Vigorito, C., Zullo, F. and Orio, F., 2007. Structured exercise training programme versus hypocaloric hyperproteic diet in obese polycystic ovary syndrome patients with anovulatory infertility: a 24-week pilot study. Human reproduction, 23 (3), pp. 642-650.

[17] Thomson, R. L., Buckley, J. D., Noakes, M., Clifton, P. M., Norman, R. J. and Brinkworth, G. D., 2008. The effect of a hypocaloric diet with and without exercise training on body composition, cardiometabolic risk profile, and reproductive function in overweight and obese women with polycystic ovary syndrome. The Journal of Clinical Endocrinology \& Metabolism, 93 (9), pp. 3373-3380.

[18] Hoeger, K. M., 2008, January. Exercise therapy in polycystic ovary syndrome. In Seminars in reproductive medicine (Vol. 26, No. 01, pp. 093-100). (C) Thieme Medical Publishers.

[19] Giallauria, F., Palomba, S., Vigorito, C., Tafuri, M. G., Colao, A., Lombardi, G. and Orio, F., 2009, July. Androgens in polycystic ovary syndrome: the role of exercise and diet. In Seminars in reproductive medicine (Vol. 27, No. 04, pp. 306315). (C) Thieme Medical Publishers.

[20] Joshi, B., Mukherjee, S., Patil, A., Purandare, A., Chauhan, S. and Vaidya, R., 2014. A cross-sectional study of polycystic ovarian syndrome among adolescent and young girls in Mumbai, India. Indian journal of endocrinology and metabolism, 18 (3), p. 317.

[21] Ashraf, G. M., Khurana, M. L., Eunice, M., Gupta, N., Diwivedi, S. N., Gulati, M. S. and Ammini, A. C., 2004. Prevalence Of Glucose Intolerance Among Adolscent And Young Women With Polycystic Ovary Syndrome In India. Indian Journal of Endocrinology and Metabolism, 6 (1), p. 9.

[22] Nidhi, R., Padmalatha, V., Nagarathna, R. and Amritanshu, R., 2011. Prevalence of polycystic ovarian syndrome in Indian adolescents. Journal of pediatric and adolescent gynecology, 24 (4), pp. 223-227.

[23] Gill, H., Tiwari, P. and Dabadghao, P., 2012. Prevalence of polycystic ovary syndrome in young women from North India: A Community-based study. Indian journal of endocrinology and metabolism, 16 (Suppl 2), p. S389.

[24] Sundararaman, P. G. and Sridhar, G. R., 2008. Psychosocial aspects of women with polycystic ovary syndrome from south India. The Journal of the Association of Physicians of India, 56, pp. 945-948. 